\title{
Gelişen Ülkelerde Çevresel Bozulma, Gelir Ve Enerji Tüketimi İlişkisi
}

\section{The Nexus between Environmental Degradation, Income and Energy Consumption in Emerging Countries}

\author{
Assoc. Prof. Dr. Cengiz Aytun (Çukurova University, Turkey) \\ Assoc. Prof. Dr. Cemil Serhat Akın (Mustafa Kemal University, Turkey) \\ Assoc. Prof. Dr. Neşe Algan (Çukurova University, Turkey)
}

\begin{abstract}
Today, especially in developing countries, environmental pollution threatens human life. Environmental quality is one of the most important sources of human welfare. Therefore, it is becoming increasingly important to understand the relationship between environmental degradation, income and energy consumption. The aim of this study is to investigate the nature of relationships among the carbon dioxide emissions, economic growth and energy consumption for emerging economies. For this purpose, Environmental Kuznets Curve hypothesis have been tested for 10 emerging economies for the years from 1980 to 2010. Data were brought together from the World Bank development indicators database. In order to test of Environmental Kuznets Curve hypothesis IPS panel unit root, Pedroni panel cointegration and FMOLS estimation methods are used. Results indicate that energy consumption has a positive and significant effect on carbon dioxide emissions. Results indicate that energy consumption has a positive and significant effect on carbon dioxide emissions. The findings also show that per capita GDP follows an inverted U-shape pattern associated with the Environmental Kuznets Curve hypothesis. This situation validates the policies which assert that environmental pollution decreases with income growth.
\end{abstract}

\section{Giriş}

Gelişmiş ya da gelişmekte olan bütün ülkeler için enerji vazgeçilmez bir üretim girdisi olup bir taraftan üretime katkı sağlarken diğer taraftan da ekonomik gelişmeyi de desteklemektedir (Uçan, vd, 2014). Ancak, enerji kullanımının bu katkıları ile birlikte çevresel bozulmaya neden olduğu göz ardı edilmemelidir. Ekonomik gelişme sürecinde enerji ve doğal kaynaklara olan talebin artması çevresel bozulmanın en büyük sebeplerinden biridir. Ekonomik gelişme ve çevre ilişkisi üzerine yapılan çalışmaların önemli bölümünde Çevresel Kuznets Eğrisi(ÇKE)nden yararlanıldığı, kullanılan yöntemlerin de benzerlikler gösterdiği görülmektedir.

S. Kuznets (1955) çalışmasında, ülkelerin kalkınma sürecinde başlangıçta kalkınma ile birlikte gelir eşitsizliğinin artacağını ancak ileriki aşamalarda ekonomik gelişme devam ettikçe gelir eşitsizliğindeki artma eğiliminin duracağını ve sonrasında ise azalacağına vurgu yapmaktadır. Kişi başına gelirden hareketle kalkınma sürecinde büyüme ve gelir eşitsizliği arasında önce artan sonra azalan bir eğilim gösteren eğri ters U şeklinde olup "Kuznets Eğrisi” olarak literatürde yerini almıştır. Söz konusu ilişkinin geçerliliği çeşitli çalışmalarda ampirik olarak sorgulanmıştır. Genel olarak literatürde ters U şeklindeki ilişkinin varlığı yönünde bir uzlaşı sağlandığ 1 görülmekle birlikte ilişkinin olmadığı yönünde de sonuçların bulunduğu görülmektedir (Morrison, 1999; Schultz, 1998; Fields ve Jakupsen,1993; Williamson, 1997). Kuznets'in yapmış olduğu çalışma, gelir ile kalkınma bileşenlerinden gelir dağılımı hakkında çıkarsamalar yapılmasına imkân sağlarken, kalkınma iktisadına yapmış olduğu katkı bununla sınırlı kalmamıştır. Özellikle çevresel kalitenin sürdürülebilmesi için Kuznets eğrisi sık sık çalışmalara ilham kaynağı olmuştur. Standart Kuznets Eğrisindeki gelir dağılımı ekseni, çevresel bozulma (kirlenme) ile yer değiştirdiğinde yeni eğri Çevresel Kuznets Eğrisi (ÇKE) olarak adlandırılmaktadır.

Ekonomik büyümenin çevre üzerine etkileri 1990'lı yıllardan itibaren artan bir şekilde ilgi odağı haline gelmiş ve konuyla ilgili yapılan çalışmalar hızla artmıştır. 1980'li yıllarla birlikte ülkelerin ekonomik büyüme performanslarına bağlı olarak enerji tüketimleri de artmış, bu durum küresel ısınma sorununa dikkatleri çekmiştir. Yenilenebilir enerji kaynakları yerine petrol, doğalgaz gibi fosil yakıtların kullanılması, orman yangınları, ev ve tesislerden çıkan dumanlar vb küresel ısınmaya neden olmaktadır. Doğanın dengesini bozan faaliyetlerin başında ise birincil enerji kaynağı olarak kullanılan fosil yakıtlar gelmektedir. Fosil yakıt kullanımı özellikle $\mathrm{CO}_{2}$ gazının salınımına neden olmaktadır. $\mathrm{CO}_{2}$ gazı toplam sera gazı emisyonunun \%60'ını oluşturmaktadır (IEA, 2013). $\mathrm{CO}_{2}$ düzeyindeki artışının önde gelen nedeni, özellikle üretim sürecinde kullanılan enerji miktarındaki artışlardır.

Ekonomik büyüme ve $\mathrm{CO}_{2}$ emisyonu arasındaki etkileşim daha çok ÇKE hipotezi aracılığı ile kurulmaktadır. Bu eğrinin oluşumunda üç ayrı etkileşim mekanizması işlemektedir. Bunlar ölçek etkisi, kompozisyon etkisi ve teknoloji etkisidir (Brock and Taylor, 2004). Ölçek etkisi ile artan üretim hacmi daha fazla enerji ihtiyacı doğurmaktadır. Özellikle az gelişmiş toplumlarda üretim miktarındaki artış birincil amaç olmaktadır. Bu amaçla artan enerji tüketimi fosil yakıt tüketimini artırmakta ve fosil yakıt tüketimi de $\mathrm{CO}_{2}$ salınımını artırarak çevreyi olumsuz yönde etkilemektedir. Kompozisyon etkisinde; üretilen ürünlerin kompozisyonunda yapılan değişikliklere dikkat çekilmektedir. Ülkeler gelişmenin ilk aşamalarında çevreye daha çok zarar veren ürünleri 
üretmektedirler. Belirli bir gelir düzeyinden sonra toplumsal bilinç artmaktadır. Temiz bir çevre yaşam kalitesinin önemli unsurlarından biri olarak algılanmaya başlanmaktadır. Bu süreçte özellikle sivil toplum örgütleri tarafından yapılan baskılar sonucu ülkenin üretim kompozisyonu daha az çevre kirletici ürünlere kaymaktadır. Teknoloji etkisinin ise çevresel bozulma üzerine beklenen etkisi negatiftir (Kumbaroglu, vd, 2008). Teknolojik gelişmelerle birlikte doğal kaynaklar yerine kullanılabilecek yapay ürünler üretilebilmekte ve üretim sonrası oluşan çevresel atıklar doğaya daha az zararlı biçimde imha edilebilmektedir. Teknolojik ilerleme ve etkin kaynak kullanımı çevresel bozulmayı azaltabilmektedir (Ma ve Stern, 2007).

Günümüzün ekonomik politikaları, büyüme odaklı oluşturulmakta ancak yaratılan gelirin bölüşümü konusunda önerilerde bulunmamaktadır. Artan gelirin uzantısı olarak refah düzeyi yükselen ülkelerde temiz teknoloji kullanımı yaygınlaşmakta, çevresel duyarlılık artmakta iken, çevresel tahribat yaratan sektörlerde üretimlerini ve ihracatlarını artırmaya yönelen gelişmekte olan ülkelerin çevresel zararları artmaktadır. Aynı zamanda gelişmiş ülkelerde tüketicilerin çevre duyarlılıklarında, çevreye ilişkin yasal düzenlemelerin sayısında ve yaptırımlarda da artış gözlenmektedir. $\mathrm{Bu}$ gelişmeler çevresel tahribat yaratan sanayilerin maliyetlerinde artış yaratarak bu sanayilerin gelişmiş ülkelerde faaliyetlerini önemli ölçüde sınırlamaktadır. Ancak bu sanayiler için çevre konusunda yasal düzenlemelerin çok sıkı uygulanmadığı gelişmekte olan ülkeler cazip bir ortam yaratmakta ve gelişmiş ülkeler üretim tesislerini gelişmekte olan ülkelere taşımaktadır. Gelişmekte olan ülkelerin bu sanayi kolları için kirlilik sığınağ 1 (cenneti) haline gelmesi literatürde "kirlilik sığınağı (ya da cenneti) hipotezi”" (Pollution Haven Hypothesis) olarak yer almaktadır. Gelişmiş ülkeler çevresel bozulmaya sebebiyet veren tesislerini doğrudan yabancı sermaye yatırımı şeklinde gelişmekte olan ülkelere taşıyarak kirlilik cennetleri yaratmaktadır (Chew, 2009). Gelişmekte olan ülkeler aleyhine oluşan bu gelişmelerin bu ülkelerin çevresel bozulma sürecine yoğun bir şekilde maruz kalmalarına neden olması, bu ülkelerde uygulanacak çevre politikalarının önemini daha da arttırmaktadır.

Çalışmanın uygulama kısmında yatay kesit gözlemleri zaman serileri ile birleştiren panel veri analizi yöntemi tercih edilmiştir. Panel veri analizi yöntemi sayesinde elde edilen bulgular zaman ve kesit etkisini dikkate almakta ve analize dahil olan değişsenler arasında doğrusallık daha az olmaktadır (Kennedy, 2006). Analiz sürecinde LLC (Levin, vd, 2002) ve IPS (Im, vd, 2003) birim kök testleri uygulanmış, eşbütünleşme testinde Pedroni'nin (1999; 2004) yöntemi takip edilmiştir. Modelin tahmininde FMOLS tahmincisi (Pedroni, 2000) kullanılmıştır. Elde edilen bulgular çerçevesinde "Çevresel Kuznets Eğrisi Hipotezi”nin incelenen gelişmekte olan ülkeler için geçerli olduğunu desteklemektedir. Aynı zamanda enerjiye olan talebindeki artışın çevresel bozulmayı artırdığı, üretim sürecinde ihtiyaç duyulan enerji ihtiyacının özellikle birincil enerji kaynağı olan fosil yakıtlarla karşılandığı sonucuna ulaşılmıştır. Bu bulgular yenilenebilir enerji kaynaklarına yönelimin bu ülkeler açısından hayati bir önem taşıdığını da desteklemektedir. Çalışmanın sonraki bölümünde ilgili literatürde yapılmış çalışmalar, üçüncü bölümde analize dahil edilen veriler e model, dördüncü bölümde ise kullanılan metod hakkında bilgiler yer almaktadır. Çalışma bulguların yer aldığı bölümü takiben sonuç bölümü ise genel değerlendirme çerçevesinde politika önerileri ile sonlandırılacaktır.

\section{Literatür}

Literatürde Çevresel Kuznets eğrisi hipotezinin test edilmesinde Denklem 1'deki model yaygın olarak kullanılmaktadır. Söz konusu model formuna kirliliğe sebep olan çok çeşitli faktörler dahil edilebilmektedir.

$$
y_{i t}=\alpha_{i}+\beta_{1 i} x_{i, t}+\beta_{2} x^{2}{ }_{i, t}+\beta_{3} z_{i, t}+\varepsilon_{i, t}
$$

Denklem 1'deki i ve t sırası ile ülkeleri ve zaman indislerini ifade etmektedir. y çevresel bozulmayı temsil eden bir göstergeyi, x geliri, z ise çevresel bozulmaya sebep olan diğer değişkenleri temsil etmektedir (Aytun, 2014a). Dinda (2004). Çevre ile gelir arasındaki olası ilişki biçimlerini $\beta$ katsayılarının anlamlılığına göre sınıflandırmaktadır. Buna göre $\beta_{1}=\beta_{2}=0$ ise $\mathrm{x}$ ile y arasında ilişki yoktur. $\beta_{1}>0$ ve $\beta_{2}=0$ ise $\mathrm{x}$ ile y arasında monoton artan bir fonksiyonel ilişki vardır. $\beta 1<0$ ve $\beta 2=0$ ise $\mathrm{x}$ ile y arasında monoton azalan bir fonksiyonel ilişki vardır. $\beta_{1}>0$ ve $\beta_{2}<0$ ise $\mathrm{x}$ ile y arasında (ÇKE hipotezini destekler nitelikte) ters $\mathrm{U}$ şeklinde bir fonksiyonel iliş̧ki vardır. $\beta_{1}<0$ ve $\beta_{2}>0$ ise $x$ ile y arasında $U$ şeklinde bir fonksiyonel ilişki vardır.

Fonksiyonel yapıya ilişkin ampirik literatür incelendiğinde uygulanan yöntem, zaman dilimi ve ülke gruplarına göre bulguların farklılaştığg göze çarpmaktadır. ÇKE hipotezinin Grossman ve Krueger (1991) tarafından ilk defa test edilmesinden bu güne bilim dünyasının çevreye duyarlılığı daha da artmıştır. Bu duyarlılığın bir sonucu olarak ÇKE hipotezi çeşitli faktörler de modele dahil edilerek yaygın olarak test edilmektedir (Aytun, 2014a). Ampirik literatür incelendiğinde panel veri analizine ilişkin araç seti geliştikçe tek ülkeli çalışmalardan ziyade panel veri analizine bir yöneliş olduğu görülmektedir. Tablo 1'de ÇKE hipotezinin testine ilişkin yapılmış çalışmalardan seçilmiş örnekler sunulmaktadır.

Öncü çalışmalar ele alındığında bu çalışmaların çevresel bozulmaya sadece gelir düzeyinin etkilerini hesaba kattığ1 görülmektedir (Galeotti ve Lanza, 2005; Holtz-Eakin ve Selden, 1995; Richmond ve Kaufmann, 2006). Sonraki dönem araştırmalarda gelir düzeyine ek olarak açıklayıcı değişken olarak enerji tüketiminin de kullanılmaya başladığı görülmektedir (Narayan ve Narayan, 2010; Omri, 2013). Son dönemlerdeki bazı çalışmalar 
ise çevresel bozulmaya kurumsal faktörleri de dahil etmeye başlamıştır. Akın (2014) BRICS ülkeleri için yapmış olduğu uygulamada özellikle kurumsal kalitenin çevresel bozulmaya etkilerini araştırmıştır. Elde ettiği bulgulara ters U biçimindeki Çevresel Kuznets Eğrisi hipotezini desteklerken, kurumsal kalite ile çevresel bozulma arasında negatif yönlü bir ilişkinin olduğu sonucuna ulaşılmıştır. Finansal serbestleşme CO2 salınımını negatif yönde, kişi başına düşen gelirin, dış ticarete serbestliğinin ve enerji tüketiminin artması ise çevresel bozulmaya pozitif yönde etki etmektedir. Devletin üretim sürecinde müdahil olarak yaratılan negatif dışsallıkları firmalara yüklemesi firmaları çevreye duyarlı daha yüksek teknolojiler kullanmaya zorlamakta, bu sayede kaynakların daha etkin kullanımı çevresel bozulmanın daha az gerçekleşmesini katkı sağlamaktadır (Lee ve Kim 2009).

\begin{tabular}{|c|c|c|c|}
\hline Çalışma & Metot & $\begin{array}{l}\text { Coğrafi-Zaman } \\
\text { Boyutu }\end{array}$ & Sonuç \\
\hline $\begin{array}{l}\text { Holtz-Eakin ve } \\
\text { Selden (1995) }\end{array}$ & Panel sabit etkiler & $\begin{array}{l}130 \text { ülke } \\
1951-1986 \\
\end{array}$ & $\begin{array}{l}\text { Monoton artan } \\
\text { eğri }\end{array}$ \\
\hline $\begin{array}{l}\text { Galeotti ve Lanza } \\
(2005)\end{array}$ & $\begin{array}{l}\text { Lineer ve log-lineer modellerin } \\
\text { karşılaştırılması }\end{array}$ & $\begin{array}{l}108 \text { ülke } \\
1971-1995\end{array}$ & $\begin{array}{l}\text { Ters U şeklinde } \\
\text { eğri }\end{array}$ \\
\hline $\begin{array}{l}\text { Richmond ve } \\
\text { Kaufman (2006) }\end{array}$ & $\begin{array}{l}\text { Panel birim kök, Pedroni } \\
\text { eşbütünleşme, Panel sabit ve rassal etk. }\end{array}$ & $\begin{array}{l}36 \text { ülke } \\
1973-1997\end{array}$ & $\begin{array}{l}\text { ÇKE hipotezi } \\
\text { geçersiz. }\end{array}$ \\
\hline Ang (2007) & ARDL sinır testi, VECM & $\begin{array}{l}\text { Fransa } \\
1960-2000\end{array}$ & $\begin{array}{l}\text { Ters U şeklinde } \\
\text { eğri }\end{array}$ \\
\hline $\begin{array}{l}\text { Apergis ve Payne } \\
(2010)\end{array}$ & $\begin{array}{l}\text { Panel birim kök, Pedroni } \\
\text { eşbütünleşme, Panel FMOLS ve } \\
\text { VECM }\end{array}$ & $\begin{array}{l}\text { Bağımsiz devletler } \\
\text { topluluğu } \\
1991-2005\end{array}$ & $\begin{array}{l}\text { Örnekleme göre } \\
\text { sonuçlar } \\
\text { değişmektedir }\end{array}$ \\
\hline $\begin{array}{l}\text { Jalil ve Mahmud } \\
\text { (2009) }\end{array}$ & ARDL sinır testi ve VECM & $\begin{array}{l}\text { Çin } \\
1975-2005\end{array}$ & $\begin{array}{l}\text { Ters U şseklinde } \\
\text { eğri }\end{array}$ \\
\hline $\begin{array}{l}\text { Lean ve Smyth } \\
(2010)\end{array}$ & $\begin{array}{l}\text { Johansen Fisher panel eşbütünleşme, } \\
\text { VECM }\end{array}$ & $\begin{array}{l}\text { ASEAN üyesi } 5 \text { ülke } \\
1980-2006\end{array}$ & $\begin{array}{l}\text { Ters U şeklinde } \\
\text { eğri }\end{array}$ \\
\hline Wang, vd. (2011) & $\begin{array}{l}\text { Panel birim kök, Pedroni } \\
\text { eşbütünleşme, Panel FMOLS ve } \\
\text { VECM }\end{array}$ & $\begin{array}{l}\text { Çin'de } 28 \text { il } \\
1995-2007\end{array}$ & U şeklinde eğri \\
\hline Özcan (2013) & $\begin{array}{l}\text { Yatay kesit bağımlılık ve heterojenliği } \\
\text { dikkate alan panel birim kök, } \\
\text { eşbütünleşme ve Panel FMOLS ve } \\
\text { VECM }\end{array}$ & $\begin{array}{l}12 \text { orta doğu ülkesi } \\
1990-2008\end{array}$ & $\begin{array}{l}\text { Ülkelere göre } \\
\text { sonuçlar } \\
\text { değişmektedir }\end{array}$ \\
\hline Aytun (2014a) & $\begin{array}{l}\text { Panel birim kök, Pedroni } \\
\text { eşbütünleşme, Panel FMOLS }\end{array}$ & $\begin{array}{l}5 \text { ayr1 gelir } \\
\text { gurubunda } 83 \text { ülke } \\
1981-2010\end{array}$ & $\begin{array}{l}\text { ÇKE hipotezi } \\
\text { geçersiz. }\end{array}$ \\
\hline Akın (2014) & $\begin{array}{l}\text { Panel sabit etkiler, rassal etkiler } \\
\text { tahmincileri ile model tahmini }\end{array}$ & $\begin{array}{l}\text { BRICS ülkeleri } \\
2001-2011\end{array}$ & $\begin{array}{l}\text { Ters U şeklinde } \\
\text { eğri }\end{array}$ \\
\hline Aytun (2014b) & $\begin{array}{l}\text { Panel birim kök, Pedroni } \\
\text { eşbütünleşme, Panel FMOLS ve } \\
\text { VECM }\end{array}$ & $\begin{array}{l}10 \text { Gelişen Ülke - } \\
1971-2010\end{array}$ & $\begin{array}{l}\text { Ters U şeklinde } \\
\text { eğri }\end{array}$ \\
\hline $\begin{array}{l}\text { Erataş ve Uysal } \\
\text { (2014) }\end{array}$ & $\begin{array}{l}\text { Panel, Westerlund ECM Panel } \\
\text { Eşbütünleşme }\end{array}$ & $\begin{array}{l}\text { BRICT } \\
1992-2010\end{array}$ & $\begin{array}{l}\text { ÇKE eğrisi } \mathrm{N} \\
\text { şeklinde }\end{array}$ \\
\hline Narayan (2010) & $\begin{array}{l}\text { Panel eşbütünleşme ve Panel Uzun } \\
\text { dönem tahmin teknikleri }\end{array}$ & $\begin{array}{l}43 \text { gelişmekte olan } \\
\text { ülke } \\
1980-2004\end{array}$ & $\begin{array}{l}\text { Ülkelerin } \\
\text { \%35'inde ÇKE } \\
\text { geçerli. }\end{array}$ \\
\hline $\begin{array}{l}\text { Robalino-Lopez, } \\
\text { vd. (2015) }\end{array}$ & Eşbütünleşme Teknikleri & $\begin{array}{l}\text { Venezuela } \\
1980-2025\end{array}$ & $\begin{array}{l}\text { ÇKE hipotezi } \\
\text { geçersiz. }\end{array}$ \\
\hline Li, vd. (2016) & PST Regresyon modeli & $\begin{array}{l}\text { Çin -30 Eyalet } \\
\text { 1997--2010 }\end{array}$ & $\begin{array}{l}\mathrm{CO}_{2} \text { için } \mathrm{ÇKE} \\
\text { geçersiz. } \mathrm{SO}_{2} \text { için } \\
\text { ÇKE geçerli. }\end{array}$ \\
\hline
\end{tabular}

Tablo 1. Çevresel Kuznets Ĕgrisini Test Eden Seçilmiş Ampirik Çalışmalar Kaynak: Wang, vd. (2011); Aytun (2014a)

Aytun (2014b) önceki çalışmalardan farklı olarak farklı eğitim seviyelerinin karbondioksit salınımına olan etkisini araştırmış, çalışmada elde edilen bulgular çevresel Kuznets eğrisi hipotezinin geçerli olduğunu desteklemiştir. Eğitim düzeyine ilişkin sonuçlar da bu hipotezi desteklemektedir. Buna göre ortaöğrenim düzeyi artarken karbondioksit salınımı da artmakta olduğu, yükseköğrenim düzeyinin artmasının ise karbondioksit salınımına azaltıcı etkisi yarattığı sonucuna ulaşılmıştır.

Ekonometrik yöntemlerdeki gelişmeler ÇKE hipotezinin de tekrar bu yöntemlerle test edilmesine yol açmıştır. Ancak panel veri analizindeki gerek heterojenitenin gerekse yatay kesit bağımlılığının dikkate alındığı çalışmalar 
(Apergis ve Payne, 2010; Ozcan, 2013; Wang, vd, 2011) konuya genel bir açıklama getirememiştir. Bu anlamda elde edilen bulguların uygulanan yönteme, coğrafi ve zaman boyutuna göre farklılaştığı görülmektedir. Gerçekleştirilecek uygulama ile gelişen ülkeler için literatüre ampirik katkı sağlanması amaçlanmaktadır.

\section{Veri ve Model}

$\mathrm{Bu}$ çalışmada çevresel Kuznets eğrisi hipotezi test edilmek üzere Dünya Bankasının Dünya Kalkınma Göstergeleri veri tabanından elde edilen seriler kullanılmıştır (World Bank, 2016). Seriler 1980-2010 dönemi için 10 gelişen ülkeyi içerecek şekilde bir araya getirilmiştir. Gelişen ülkeler olarak Brezilya, Çin, Macaristan, Meksika, Malezya, Türkiye, Güney Afrika, Mısır, Endonezya ve Hindistan'a ait veriler kullanılmıştır. Kullanılan seriler ve serilerin elde edildiği kaynak Tablo 2'de sunulmaktadır. Ek olarak serilere ilişkin tanımlayıcı istatistikler ise Tablo 3 'te verilmiştir.

\begin{tabular}{|lll|}
\hline SERI & SERIYE ILIŞKIN AÇIKLAMA & KAYNAK \\
\hline CO2 & Kişi başına CO2 emisyonu (metrik ton) & WDI $^{\mathrm{a}}$ \\
\hline GDP & Kişi başına Gayrisafi Yurtiçi Hasıla (2005 yılı sabit fiyatlarıyla - USD) & WDI $^{\mathrm{a}}$ \\
\hline ENR & Kişi başına enerji kullanımı (kg olarak petrole eşdeğer) & WDI $^{\mathrm{a}}$ \\
\hline
\end{tabular}

Tablo2. Serilere Ilişskin Açılamalar ve Kaynaklar Kaynak: ${ }^{a}$ The World Bank World Development Indicators

\begin{tabular}{|l|l|l|l|l|l|}
\hline & Gözlem & Ortalama & Standart Hata & Minimum & Maksimum \\
\hline CO2 & 309 & 3.549957 & 2.645075 & 0.498710 & 10.35715 \\
\hline GDP & 309 & 3866.384 & 2861.662 & 220.4417 & 11533.82 \\
\hline ENR & 309 & 1311.877 & 796.4798 & 293.5117 & 2961.354 \\
\hline
\end{tabular}

Tablo 3. Tanımlayıcı Istatistikler

Çevresel Kuznets Eğrisi hipotezinin testinde zaman serisi analiz araçlarının yanısıra panel veri analizi araçları da kullanılabilmektedir. Bu çalışmada Denklem 2'de ifade edilmiş olan model panel veri araçları ile analiz edilecektir. Söz konusu model çevresel bozulma ile gelir arasındaki ilişkiyi test etmek üzere yaygın olarak kullanılmaktadır (Dinda, 2004).

$$
C O 2_{i t}=\alpha_{i}+\beta_{1 i} G D P_{i, t}+\beta_{2} G D P^{2}{ }_{i, t}+\beta_{3} E N R_{i, t}+\varepsilon_{i, t}
$$

Çalışmada çevresel bozulma göstergesi olarak kullanılan karbondioksit emisyonu düzeyini açıklamak üzere Apergis ve Payne (2010) ve Aytun (2014a) tarafından kullanılan panel veri analizi yaklaşımı izlenecektir. Modelde karbondioksit salınımının uzun dönemdeki en önemli açıklayıcı değişkenleri olarak kişi başına gelir ve enerji tüketimi düzeyleri kullanılmıştır.

Buna göre Denklem 2'de i indisi ülkeleri, t indisi zamanı ifade etmektedir. Uygulamada çevresel bozulma (CO2), gelir düzeyi (GDP) ve enerji tüketimi (ENR) serilerinin seviye değerleri kullanılmıştır. Modeldeki $\beta_{1}$ ve $\beta_{2}$ katsayıları gelir düzeyinin karbondioksit salınıma etkisini temsil etmektedir. $\beta_{3}$ katsayısı ise enerji tüketiminin karbondioksit emisyonuna olan uzun dönemli etkisini göstermektedir. Denklem 2'de $\beta_{1}$ katsayıs1 pozitif ve $\beta_{2}$ katsayısı negatif işaretli ise GDP ile CO2 arasında (ÇKE hipotezini destekler nitelikte) ters U şeklinde bir fonksiyonel ilişki vardır. Ek olarak literatürde enerji tüketiminin karbondioksit salınımını arttırdığı genel olarak kabul edilmektedir. Bu nedenle $\beta_{3}$ katsayısının işaretinin pozitif olması beklenmektedir (Apergis ve Payne, 2010; Dinda, 2004; Wang, vd, 2011).

\section{Metod}

Panel veri analizinin ardında yatan temel varsayım bütün bireylerin havuzlanarak (bir araya getirilerek) model parametrelerinin tek bir birey gibi ortak olarak tahmin edilebileceğidir. Verilerin bu şekilde bir araya getirilmesi yatay kesitler ve zaman serileri arasındaki önceden gözlenemeyen değişimleri ortaya çıkararak çeşitli avantajlar sağlamaktadır (Asteriou ve Hall, 2007). Bu avantajlardan birincisi özellikle yatay kesit verilerde açıklanamayan, farklı birey parametreleri arasındaki heterojenliği göz önünde bulundurabilmesidir. İkincisi; farklı bireylere, firmalara, ülke ya da şehirlere ait etkilerin heterojen olduğunu ayırt edebilmesidir. Üçüncü olarak panel veri; yatay kesit ve zaman serisi analizi enformasyonunu birleştirerek değişkenler arasında daha az doğrusal bağlantı, daha fazla serbestlik derecesi ve etkinlik sağlamaktadır. Dördüncü olarak, panel veri dinamik uyarlamaları açıklamada daha yeteneklidir. Yatay kesit verileri dinamik dönüşümler hakkında hiçbir şey söyleyemez. Panel veri analizi bu dinamik tepkileri mevcut bilgiyi kullanarak çok uzun zaman serilerine ihtiyaç duymaksızın açıklayabilmektedir. Beşinci ve son olarak, panel veri analizi saf zaman serisi ya da saf yatay kesit verilerle kolayca ölçülemeyen etkileri belirleme ve ölçme kabiliyetine sahiptir. Üretim fonksiyonlarının analizinde, ölçek ekonomilerinin etkilerinin teknolojik ilerlemeden ayırt edilmesi bu duruma örnek olarak verilebilir (Baltagi, 2005; Kennedy, 2006).

Uygulamada öncelikle birim kök testleri ile serilerin durağanlıkları araştırılacaktır. Ardından eşbütünleşme testleri uygulanıp eşbütünleşik seriler için model katsayıları tahmin edilecektir. 
Panel veri analizlerinde serilerin durağanlıklarının ilk aşamada araştırılması gerekmektedir. Bu çalışmada LLC (Levin, vd, 2002) ve IPS (Im, vd, 2003) panel birim kök testleri seçilerek uygulanmıştır. LLC ve IPS testleri Denklem 3'teki gibi ifade edilen birinci dereceden otoregresif bir denkliği temel almaktadırlar.

$$
\mathrm{Y}_{i t}=\rho_{\mathrm{i}} \mathrm{Y}_{i t-1}+\Gamma_{\mathrm{it}} \theta_{\mathrm{it}}+\varepsilon_{i t}
$$

$\Gamma_{\text {it }}$ modeldeki sabit etkileri ve trend katsayılarını, $\rho_{\mathrm{i}}$ otoregresif katsayıy1, $\varepsilon_{i t}$ hata terimini ifade etmektedir. Bu modelde $\rho_{\mathrm{i}}$ 'nin 1'e eşit olması Y'nin bugünkü değerlerinin tamamen geçmiş değerlerinden etkilendiği anlamına gelmektedir. LLC testinde $\mathrm{H}_{0}$ hipotezi serilerin ortak bir otoregresif parametreye sahip olduğunu $\left(H_{0}: \rho_{\mathrm{i}}=\rho=1\right)$ öne sürmektedir. IPS testi ise zaman serisinde kullanılan ADF testinin panel veriye uyarlanmış bir versiyonudur. Birimler arasındaki heterojenlik göz önünde bulundurularak her bir birim için ayrı ayrı birim kök test edilir $\left(H_{0}: \rho_{\mathrm{i}}=1\right)$. Panel için elde edilen test istatistiği bireylere özgü istatistiklerin ortalamasıdır (Baltagi, 2005). Gerçekleştirilen Monte Carlo simülasyonları IPS testinin LLC testinden daha güçlü olduğunu ortaya koymaktadır (Tatoğlu, 2012).

Makro ekonomik serilere ilişkin araştırmalarda seriler seviye değerlerinde durağan değilken doğrusal bileşimleri durağan olabilmektedir. Bu nedenle serilerin birinci dereceden durağan olduklarının tespitinden sonra aralarında bir eşbütünleşme ilişkisinin olup olmadığı araştırılmalıdır. Bu çalışmada Pedroni (1999; 2004) tarafından geliştirilen panel eşbütünleşme testi uygulanacaktır. Bu testte birimlere özgü sabit ve trend etkileri ayrı ayrı göz önünde bulundurularak heterojenliğe olanak tanınmaktadır. Pedroni $(1999 ; 2004)$ birden fazla açıklayıcı değişkenli paneller için geliştirdiği eşbütünleşme testinde iki gurupta yedi adet test istatistiği geliştirmiştir. İlk dört test istatistiği gurup-içi (within-dimension) istatistikler olarak adlandırılmaktadır. Bunlar sırasıyla varyans oranı, nonparametrik PP (Philips ve Perron) tipi $\rho$, nonparametrik PP tipi t ve Dickey Fuller (DF) tipi t istatistikleri olarak adlandırılırlar. Bu dört istatistik hesaplanırken eşbütünleşme modeline ait otoregresif katsayılar ( $\phi i)$ homojen kabul edilerek havuzlanmaktadır. İkinci guruptaki üç test istatistiği ise guruplar-arası (between-dimension) istatistikler olarak adlandırılmaktadır. Üç istatistik de hesaplanırken her bir birim için oluşturulan eşbütünleşme modeline ait otoregresif katsayılar heterojen kabul edilir. Her iki gurup için $\mathrm{H}_{0}$ hipotezi "panel için eşbütünleşme yoktur" şeklindedir. Alternatif hipotezler ise homojenliği varsayan gurup-içi testlerde "panel için eşbütünleşme vardır" şeklinde iken, heterojenliği varsayan guruplar-arası testlerde "bazı birimler (i) için eşbütünleşme yok iken, diğer birimler için vardır” şeklindedir. Test istatistikleri asimptotik olarak standart normal dağılıma sahiptir.

Panel veri analizinde eşbütünleşik heterojen serilere ilişkin tahminde Fully Modified OLS (FMOLS) yaygın olarak kullanılmaktadır (Pedroni, 2000). Panel FMOLS tahmincisi her bir zaman serisi için Denklem 2'den elde edilen sonuçlar $\beta_{F M i}^{*}$ kullanılarak $\hat{\beta}_{G F M}^{*}=N^{-1} \sum_{i=1}^{N} \beta_{F M i}^{*}$ elde edilmektedir.

\section{Bulgular}

Tablo 4'te gelişmekte olan 10 ülke için yapılan LLC (Levin, vd, 2002) ve IPS (Im, vd, 2003) panel birim kök testi sonuçları yer almaktadır. LLC testinde serilerin ortak bir otoregresif parametreye sahip olduğu hipotezi $\left(H_{0}: \rho_{\mathrm{i}}=\rho=1\right)$ test edilmiştir. IPS testinde ise birimler arasındaki heterojenlik göz önünde bulundurularak her bir birim için ayrı ayrı sıfır hipotezi $\left(H_{0}: \rho_{\mathrm{i}}=1\right)$ test edilmiştir. LLC ve IPS test sonuçlarına göre CO2, GDP ve ENR serilerinin seviyede birim kök içerdikleri görilmektedir. Serilerin birinci farkları alındığında ise her iki testte de sıfır hipotezi \%1 anlamlılık seviyesinde reddedilmektedir. Elde edilen bulgulara dayanarak serilerin birinci dereceden durağan olduklarına karar verilmiştir.

\begin{tabular}{|c|c|c|}
\hline Seriler & $\begin{array}{c}\text { LLC } \\
(\text { Levin, vd, 2002) } \\
\left(H_{0}: \rho_{\mathrm{i}}=\rho=1\right)\end{array}$ & $\begin{array}{c}\text { IPS } \\
\text { IPS (Im, vd, 2003) } \\
\left(H_{0}: \rho_{\mathrm{i}}=1\right) .\end{array}$ \\
\hline $\mathrm{CO} 2$ & 0.14033 & $3.82541^{\mathrm{a}}$ \\
\hline GDP & 5.36783 & 4.78446 \\
\hline $\mathrm{GDP}^{2}$ & 8.45227 & 6.10510 \\
\hline ENR & 3.57874 & 1.12923 \\
\hline$\triangle \mathrm{CO} 2$ & $-9.75965 * * *$ & $-11.5037 * * *$ \\
\hline$\Delta \mathrm{GDP}$ & $-7.78767 * * *$ & $-7.24903 * * *$ \\
\hline$\Delta \mathrm{GDP}^{2}$ & $-4.11700 * * *$ & $-5.36945 * * *$ \\
\hline$\Delta \mathrm{ENR}$ & $-5.43338 * * *$ & $-8.69625 * * *$ \\
\hline \multicolumn{3}{|c|}{$\begin{array}{l}\text { Not: *** } \mathrm{p}<0.01, * * \mathrm{p}<0.05,{ }^{*} \mathrm{p}<0.1 \text { Optimal gecikme } \\
\text { uzunluğu Schwarz bilgi kriterine göre belirlenmiştir. Test } \\
\text { istatistiğinin yanında a indisinin olmas sabitli modeli, } \\
\text { olmaması sabit ve trendli modeli ifade etmektedir. Spektral } \\
\text { tahmin sürecinde bant genişliği Newey-West ile tespit } \\
\text { edilmiş ve Bartlett kerneli kullanılmıştır. }\end{array}$} \\
\hline
\end{tabular}

Tablo 4. LLC ve IPS Panel Birim Kök Testi Sonuçları 
Serilerin birinci dereceden durağan olduklarına karar verilmesinden sonra Pedroni (1999; 2004) panel eşbütünleşme testi gerçekleştirilmiştir. Tablo 5'te yer alan Pedroni (1999; 2004) panel eşbütünleşme testi sonuçlarına göre Gurup içi Panel- $\rho$, Panel-PP ve Panel-ADF testlerinde $\mathrm{H}_{0}$ hipotezi reddedilmiştir. Guruplar-arası test istatistiklerine bakıldığında ise Group - PP ve Group - ADF testlerinde $\mathrm{H}_{0}$ hipotezi reddedilmektedir. Genel bir bakış ile gerçekleştirilen testler seriler arasında eşbütünleşme ilişkisi olduğuna yönelik güçlü kanıt oluşturmaktadır. Sonuç olarak gelişen 10 ülke için bir araya getirilen serilerin eşbütünleşik olduğuna karar verilmiştir.

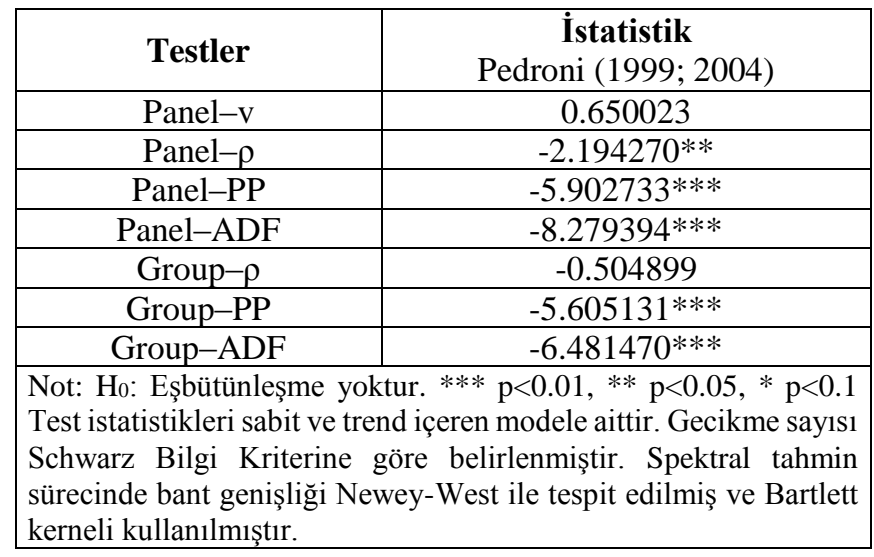

Tablo 5. Pedroni Eşbütünleşme Testi Sonuçları

Çevresel Kuznets Eğrisinin varlığına yönelik oluşturulan model (Denklem 2) Fully Modified OLS (FMOLS) tahmincisi (Pedroni, 2000) ile tahmin edilmiştir. Tablo 6'da raporlanan sonuçlara göre $\beta_{1}$ katsayısının pozitif ve anlamlı iken $\beta_{2}$ katsayısının negatif ve anlamlı olduğu görülmektedir. Özetle, karbondioksit emisyonu (CO2) ile gelir düzeyine (GDP) ilişkin bulguların Çevresel Kuznets Eğrisi hipotezini desteklediği görülmektedir. Bulgular söz konusu 10 gelişen ülke için gelişmenin ilk aşamalarında gelir artışının çevresel bozulmayı arttırdığını ancak belirli bir aşamadan sonra bu etkinin ortadan kalkarak tersine döndüğünü göstermektedir. ÇKE hipotezi çevre kirliliğine karşı hiçbir şey yapmamanın en iyi politika olduğunu ima etmektedir. Bu anlamda gelir artışı ile otomatik olarak çevre kirliliğinin azalacağını öne süren ÇKE hipotezi gelişen 10 ülke örneklemi için desteklenmektedir.

Uygulamada ek olarak elde ettiğimiz bir bulgu ise enerji tüketimi ile karbondioksit salınımına ilişkindir. Enerji tüketimine ilişkin $\beta_{3}$ katsayısının literatürle uyumlu bir şekilde pozitif ve anlamlı olduğu görülmektedir. Buna göre gelişen 10 ülkede kişi başına bir kilogram petrole eşdeğer tüketim yapılmasının karbondioksit emisyonunu 0.002455 metrik ton arttırdığı görülmektedir.

\begin{tabular}{|l|c|}
\hline $\mathrm{CO} 2$ & FMOLS \\
\hline$\left(\beta_{1}\right) \mathrm{GDP}$ & $0.000426 * * *$ \\
\hline$\left(\beta_{2}\right) \mathrm{GDP}{ }^{2}$ & $-1.36 \mathrm{E}-08^{*}$ \\
\hline$\left(\beta_{3}\right) \mathrm{ENR}$ & $0.002455^{* * *}$ \\
\hline Sonuç & $\begin{array}{c}\beta_{1}>0 \text { ve } \beta_{2}<0 \\
\text { ÇKE hipotezi geçerli }\end{array}$ \\
\hline Not: $* * * \mathrm{p}<0.01, * * \mathrm{p}<0.05,{ }^{*} \mathrm{p}<0.1$ \\
\hline
\end{tabular}

Tablo 6. FMOLS Tahmin Sonuçları

\section{Sonuç}

Kuznets 1955 yılındaki temel eserinde ülkelerin kalkınma sürecinde yaşadıkları gelir dağılımı değişmelerine dikkat çekmiştir. Kuznets'e göre ülkelerde gelişme sürecinin ilk aşamalarında gelir dağılımı bozulmakta, ancak belirli bir aşama sonrası gelir dağılımı düzelmeye başlamaktadır. Kuznets'in çalışması ile kalkınmanın bir boyutu olarak gelir dağılımı adaletine dikkat çekilmiştir. Bu durum araştırmacılara benzer süreçlerin kalkınmanın çevre boyutunda da geçerli olup olmadığını araştırma konusunda ilham vermiştir. Standart Kuznets Eğrisi bu bakış açısı ile Çevresel Kuznets Eğrisine dönüşmüştür. Gelişen ülkelerde sanayileşmenin getirdiği çevresel sorunlar bu sorunlara müdahale edip etmeme konusunda kararsızlığa yol açmaktadır. Kuznets'in hipotezinin çevre kirliliği boyutunda geçerli olması, aktif politikaları gereksiz kılmaktadır. Bu anlamda ülkeler milli gelirlerini adım adım yükselttikçe çevresel bozulma önce artacak bir aşamadan sonra azalmaya başlayacaktır. Günümüzde özellikle gelişen ülkelerin ciddi çevre sorunlarıyla karşı karşıya olduğu düşünülürse ÇKE hipotezinin bu ülkelerin uygulayacakları çevre politikaları açısından önemi daha iyi anlaşılmaktadır. Araştırmada bu nedenle gelişen 10 ülkenin 1980-2010 dönemi verileri kullanılmıştır. Serilerin birinci dereceden durağan olduklarının tespit 
edilmesinden sonra serilerin eşbütünleşik olduğu görülmüştür. Eşbütünleşik serilere ilişkin model Panel Fully Modified OLS tahmincisi ile tahmin edilmiştir. Bulgular gelişmekte olan ülkeler örneklemi için Çevresel Kuznets Eğrisi hipotezinin geçerli olduğuna işaret etmektedir. Böylesi bir durum gelir düzeyinin artması ile çevresel bozulmanın giderek azalacağı görüşünü desteklemektedir. Gelişen ülkelerde uzun dönemde fosil kaynak kullanımını azaltılarak çevresel kirliliği ve fosil kaynaklara olan bağımlılığın azaltılması olasıdır. Çevresel kirliliği azaltacak sürdürülebilir bir büyüme performansı için yenilenebilir enerji politikaları oluşturularak, bu ülkelerin gelişmiş ülkelerin kirlilik sığınakları haline gelmemesi konusunda hassasiyet gösterilmesi gerekmektedir. Çalışmamızda ek olarak çevresel bozulmaya etkisi olabilecek kurumsal ve sosyo-ekonomik faktörlerin de araştırılması gelecek çalışmalara öneri olarak sunulmaktadır.

\section{Kaynakça}

- Akın, 2014. "Kurumsal Kalitenin Çevre Üzerine Olan Etkileri: BRICS Ülkeleri Üzerine Bir Uygulama”, Uluslararası Alanya İsletme Fakültesi Dergisi, 6(2), 1-8.

- Ang, 2007. "CO2 emissions, energy consumption, and output in France" Energy Policy, 35(10), 4772-4778.

- Apergis ve Payne, 2010. "The emissions, energy consumption, and growth nexus: Evidence from the commonwealth of independent states", Energy Policy, 38(1), 650-655.

- Asteriou ve Hall, 2007. Applied econometrics : A modern approach using eviews and microfit. Palgrave Macmillan, New York.

- Aytun, 2014a. "Çevresel Kuznets Eğrisi Hipotezi: Panel veri Analizi”, Akademik Bakış, (44), p. 1-14.

- Aytun, 2014b. "Gelişen Ekonomilerde Karbondioksit Emisyonu, Ekonomik Büyüme ve Eğitim Arasındaki İlişki: Panel Veri Analizi”, The Journal of Academic Social Science Studies, (27), 349-362.

- Baltagi, 2005. Econometric Analysis of Panel Data (3rd ed.). John Wiley \& Sons, Chichester.

- Brock ve Taylor, 2004. "Economic Growth and the Environment: A Review of Theory and Empirics", NBER Working Paper Series, Working Paper no: 10854

- Chew, 2009. "Foreign Direct Investment, Pollution and Economic Growth: Evidence form Malaysia". Applied Economics, 41, 1709-1716

- Dinda, 2004. "Environmental Kuznets Curve Hypothesis: A Survey”, Ecological Economics, 49(4), 431455.

- Erataş ve Uysal, 2014. "Çevresel Kuznets Eğrisi yaklaşımının BRICT Ülkeleri kapsamında Değerlendirilmesi”, Iktisat Fakültesi Mecmuası, 64(1), 1-25.

- Fields ve Jakubson, 1994. New Evidence on the Kuznets Curve, Cornell University, Ithaca NY.

- Grossman ve Krueger, 1991. "Environmental Impacts of a North American Free Trade Agreement" (Working Paper No. 3914). National Bureau of Economic Research.

- Galeotti ve Lanza, 2005. "Desperately seeking environmental Kuznets", Environmental Modelling \& Software, 20(11), 1379-1388.

- Holtz-Eakin ve Selden, 1995. "Stoking the fires? CO2 emissions and economic growth", Journal of Public Economics, 57(1), 85-101.

- IEA, 2013. CO2 Emissions From Fuel Combustion Highlights. IEA Publications, Paris.

- Im, Pesaran ve Shin, 2003. "Testing for unit roots in heterogeneous panels", Journal of Econometrics, 115(1), 53-74.

- Jalil ve Mahmud, 2009. "Environment Kuznets curve for CO2 emissions: A cointegration analysis for China", Energy Policy, 37(12), 5167-5172.

- Kennedy, 2006. Ekonometri Kılavuzu (Ş. Açıkgöz \& M. Sarımeşeli, Trans.). Gazi Kitabevi, Ankara.

- Kumbaroglu, Karali ve Arikan, 2008. "CO2, GDP and RET: An Aggregate Economic Equilibrium Analysis for Turkey”, Energy Policy, 36, 2694-2708.

- Kuznets, 1955. "Economic Growth and Income Inequality”, The American Economic Review, 45(1), 1-28.

- Lean ve Smyth, 2010. "CO2 emissions, electricity consumption and output in ASEAN", Applied Energy, 87(6), 1858-1864.

- Lee ve Kim, 2009. "Both institutions and policies matter but differently for different income groups of countries: determinants of long-run economic growth revisited", World Development, 37(3), 533-49.

- Levin, Lin ve Chu, 2002. "Unit root tests in panel data: asymptotic and finite-sample properties", Journal of Econometrics, 108(1), 1-24. 
- Li, Yan, An, Chen ve Shen, 2016. "The coordination between China's economic growth and environmental emission from the Environmental Kuznets Curve viewpoint". Natural Hazards, 1-20. http://doi.org/10.1007/s11069-016-2314-0

- Ma ve Stern, 2007. "China's Carbon Emissions 1971-2003”, Rensselaer Working Papers in Economics, Rensselaer Polytechnic Institute, Department of Economics Number 0706.

- Morrisson, 2000. "Historical Perspectives on Income Distribution: The Case of Europe," in Atkinson and Bourguignon, eds., Handbook of Income Distribution. Elsevier, Amsterdam

- Narayan ve Narayan, 2010. "Carbon dioxide emissions and economic growth: Panel data evidence from developing countries”, Energy Policy, 38(1), 661-666.

- Omri, 2013. "CO2 emissions, energy consumption and economic growth nexus in MENA countries: Evidence from simultaneous equations models", Energy Economics, 40, 657-664.

- Ozcan, 2013.'The nexus between carbon emissions, energy consumption and economic growth in Middle East countries: A panel data analysis”, Energy Policy, 62, 1138-1147.

- Pedroni, 1999. "Critical Values for Cointegration Tests in Heterogeneous Panels with Multiple Regressors", Oxford Bulletin of Economics and Statistics, 61(S1), 653-670.

- Pedroni, 2000. "Fully modified OLS for heterogeneous cointegrated panels", B. H. Baltagi (Ed.), Advances in Econometrics (Vol. 15, s. 93-130). Bingley: Emerald.

- $\quad$ Pedroni, 2004. "Panel Cointegration: Asymptotic and Finite Sample Properties of Pooled Time Series Tests With an Application to the PPP Hypothesis", Econometric Theory, 20(03), 597-625.

- Richmond ve Kaufmann, 2006. "Is there a turning point in the relationship between income and energy use and/or carbon emissions?”, Ecological Economics, 56(2), 176-189.

- Robalino-Lopez, Mena-Nieto ve Garcia-Ramos, 2015. "Studying the relationship between economic growth, CO2emissions, and the environmental Kuznets curve in Venezuela (1980-2025)", Renewable and Sustainable EnergyReviews, 41, 602-614.

- Schultz, 1998. "Inequality in the Distribution of Personal Income in the World: How it is Changing and Why", Journal of Population Economics, 11(3), 307-44.

- Tatoğlu, 2012. İleri Panel Veri Analizi. Beta Yayıncılık, İstanbul.

- Uçan, Arıŏlu ve Yücel, 2014. "Energy Consumption and Economic Growth Nexus: Evidence from Developed Countries in Europe", International Journal of Energy Economics and Policy, 4(3), 411-419.

- Wang, Zhou, Zhou ve Wang, 2011. “CO2 emissions, energy consumption and economic growth in China: A panel data analysis”, Energy Policy, 39(9), 4870-4875.

- Williamson, 1997. “Globalization and inequality, past and present”, The World Bank Research Observer, 12(2), 117-135.

- World Bank, 2016. World Development Indicators, http://databank.worldbank.org/data/ (Erişim: 20.03.2016)

Bu çalışma Çukurava Üniversitesi Bilimsel Araştırma Projeleri birimi tarafından desteklenmiştir. Proje no: SBA2016-7001 